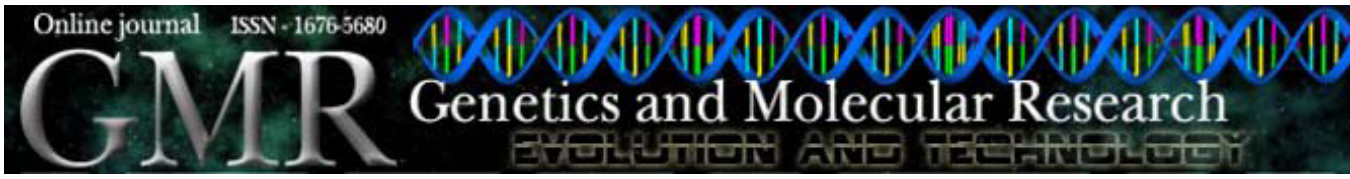

\title{
Low productivity of ribonucleotide reductase in Saccharomyces cerevisiae increases sensitivity to stannous chloride
}

\author{
T.S. Basso, C. Pungartnik and M. Brendel \\ Departamento de Ciências Biológicas, Universidade Estadual de Santa Cruz, \\ Salobrinho, Ilhéus, BA, Brasil \\ Corresponding author: M. Brendel \\ E-mail: martinbrendel@yahoo.com.br
}

Genet. Mol. Res. 7 (1): 1-6 (2008)

Received October 25, 2007

Accepted December 11, 2007

Published January 8, 2008

\begin{abstract}
Ribonucleotide reductase (RNR) of the yeast Saccharomyces cerevisiae is a tetrameric protein complex, consisting of two large and two small subunits. The small subunits $\mathrm{Y} 2$ and $\mathrm{Y} 4$ form a heterodimer and are encoded by yeast genes $R N R 2$ and $R N R 4$, respectively. Loss of Y 4 in yeast mutant $r n r 4 \Delta$ can be compensated for by up-regulated expression of $\mathrm{Y} 2$, and the formation of a small subunit Y2Y2 homodimer that allows for a partially functional RNR. However, $r n r 4 \Delta$ mutants exhibit slower growth than wild-type (WT) cells and are sensitive to many mutagens, amongst them UVC and photo-activated mono- and bi-functional psoralens. Cells of the haploid $r n r 4 \Delta$ mutant also show a 3- to 4-fold higher sensitivity to the oxidative stress-inducing chemical stannous chloride than those of the isogenic WT. Both strains acquired increased resistance to $\mathrm{SnCl}_{2}$ with age of culture, i.e., 24-h cultures were more sensitive than cells grown for 2, 3,4 , and 5 days in liquid culture. However, the sensitivity factor of three to four (WT/mutant) did not change significantly. Cultures of the $r n r 4 \Delta$ mutant in stationary phase of growth always showed higher frequency of budding cells (budding index around 0.5) than those of the corresponding WT (budding index $<0.1$ ), pointing to a delay of mitosis/cytokinesis.
\end{abstract}

Key words: Ribonucleotide reductase; Saccharomyces cerevisiae; Mutagen sensitivity; Stannous chloride; Budding index 


\section{INTRODUCTION}

Ribonucleotide reductase (RNR) has a central role in cellular metabolism as it catalyzes, using free-radical chemistry (Thelander and Reichard, 1979; Stubbe and van Der Donk, 1998), the reduction of ribonucleoside diphosphates to the corresponding deoxyribonucleoside diphosphates, an essential step in de novo biosynthesis of deoxyribonucleoside triphosphates (dNTPs). The active RNR of yeast is a tetrameric protein complex consisting of two large subunits, either a Y1Y1 homo- or a Y1Y3 heterodimer and two small ones that form the Y2Y4 heterodimer (Huang and Elledge, 1997; Wang et al., 1997). Y 2 and Y4 are encoded by yeast genes $R N R 2$ and $R N R 4$ and share extensive sequence homologies to all characterized Rnrp small subunits from other organisms. Rnr4p is unique in that it lacks 6 of 16 residues conserved in nearly all Rnr2ps, including 3 residues involved in coordinating iron. As a result, Rnr4p cannot accommodate a diiron center. Rnr4p is required for viability in some yeast strains under all conditions and in some others only at lower temperature (Huang and Elledge, 1997; Wang et al., 1997).

The critical role of adequate RNR activity in providing correct dNTP pools during the cell cycle and after repair-requiring DNA damage is secured by complex and multilayered mechanisms of transcriptional and feedback regulation (Elledge et al., 1993; Yao et al., 2003; Klinkenberg et al., 2006; An et al., 2006). Imbalanced dNTP pools with one (Brendel, 1985) or all (Chabes et al., 2003) dNTPs at higher-than-normal concentrations lead to increased mutation rates, while an $r n r 4 \Delta$ mutant with a Y2Y2 small subunit homodimer that contains 15 times less diferric-tyrosyl radical co-factor (Perlstein et al., 2005) and apparently lower dNTP pools exhibits slow growth, increased mutagen sensitivity and lower induced mutagenesis (Strauss et al., 2007).

When demand in yeast for dNTPs is low, the Y2Y4 small RNR heterodimer colocalizes in the nucleus whereas the large subunit Y1Y1 homodimer resides outside the nuclear membrane (Yao et al., 2003). Upon DNA damage, when demand for dNTPs is high, the Y2Y4 heterodimers leave the nucleus as one protein complex (An et al., 2006) to bind to the large RNR homo- or heterodimer subunit (Lee and Elledge, 2006; An et al., 2006).

Stannous chloride $\left(\mathrm{SnCl}_{2}\right)$ is a weak mutagen as defined by its genotoxicity in unicellular prokaryotes (Bernardo-Filho et al., 1994; Dantas et al., 1996) and eukaryotes (Pungartnik et al., 2005) as well as with respect to its DNA interactions in mammalian cells (McLean and Kaplan, 1979). $\mathrm{SnCl}_{2}$ is known to produce reactive oxygen species (ROS) (McLean et al., 1983; Dantas et al., 1999), most probably via Fenton-like reactions (McLean et al., 1983), and thus the genetic endowment of yeast with anti-oxidative defense systems, e.g., superoxide dismutases, catalases, glutathione, and their oxidative stress-induced expression could contribute to $\mathrm{Sn}^{2+}$-resistance (Viau et al., 2006).

Anaerobically growing microorganisms, especially obligate anaerobes, generally have a higher metal sensitivity than aerobically living microbial species. The facultative anaerobe yeast Saccharomyces cerevisiae can grow in the presence or absence of respiratory metabolism in glucose-containing cultures (sugar fermentation, followed by alcohol respiratory metabolism after the diauxic shift); therefore, cells of different stages of the same culture serve as a good model to test the influence of general metabolism on sensitivity to $\mathrm{Sn}^{2+}$ (Viau et al., 2006). Since Strauss et al. (2007) have shown that the

Genetics and Molecular Research 7 (1): 1-6 (2008) www.funpecrp.com.br 
rnr $4 \Delta$ mutant strain has a higher-than-wild-type (WT) budding index, and exponentially growing (LOG) cells are known to be much more sensitive to $\mathrm{SnCl}_{2}$ exposure (Viau et al., 2006), we hypothesized that the lack of fully functional RNR would leave the cells in a LOG-type growth phase and more sensitive to $\mathrm{SnCl}_{2}$.

\section{MATERIAL AND METHODS}

\section{Yeast strains and growth conditions}

The genotypes of the isogenic yeast strains used in this study are haploid WT BY10000 (BY4742) Mata his $3 \Delta 1$ leu2 $\Delta 0$ lys2 $\Delta 0$ ura $3 \Delta 0$ and haploid mutant $r n r 4 \Delta$ which contains the disruption cassette YGR180c::kanMX4 in its RNR4 gene [EUROSCARF]. Media, solutions and buffers were prepared according to Burke et al. (2000). Complete medium (YPD - 2\% glucose, $2 \%$ peptone, $1 \%$ yeast extract) was used for routine growth of yeast cells. To ascertain yeast respiratory competence and for elimination of spontaneously accumulated petites, all strains were pre-grown on YPG media (glucose replaced by $2 \%$ glycerol) before being grown in YPD. Exponential growth of cells (LOG) was ascertained by microscopic counting (cell titer $<2 \times 10^{7} / \mathrm{mL}$ with budding frequency $>30 \%$ ).

\section{Yeast exposure to $\mathrm{SnCl}_{2}$ and survival}

Stationary (STAT) cells were harvested from YPD liquid shaking cultures $\left(30^{\circ} \mathrm{C}\right)$ after growth for 1 to five days. Sensitivity to $\mathrm{SnCl}_{2}\left[25 \mathrm{mM}, 60 \mathrm{~min}\right.$ at $30^{\circ} \mathrm{C}$ ] of twice saline-washed STAT cell suspensions was routinely determined in saline $(0.9 \% \mathrm{NaCl})$. Thereafter, $\mathrm{SnCl}_{2}$-mediated cell aggregates were de-clumped in $0.067 \mathrm{M}$ phosphate buffer, $\mathrm{pH}$ 7.4, followed by vigorous vortexing before further dilution in phosphate buffer and plating (Pungartnik et al., 2005). Cells were plated on YPD and survival was determined after 2 days at $30^{\circ} \mathrm{C}$. The results presented are the means of at least 3 independent experiments, and the standard deviation and statistical analyses were calculated by GraphPad Prism ${ }^{\circledR}$ program.

\section{RESULTS AND DISCUSSION}

Cells of yeast mutant $r n r 4 \Delta$ exhibited 3- to 4-fold higher sensitivity to $\mathrm{SnCl}_{2}$ exposure than that of the isogenic WT. Both WT and the sensitive $r n r 4 \Delta$ mutant acquired increased resistance to $\mathrm{SnCl}_{2}$ with age, i.e., time of the STAT phase, with highest resistance reached after five days of liquid culture. However, the sensitivity factor of three to four (WT/mutant) did not change significantly (Figure 1). Cultures of the rnr4s mutant in STAT phase always showed a higher frequency of budding cells (budding index not lower than 0.5 ) than did the corresponding WT cells (budding index $<0.1$, Figure 2 ) pointing to a delay of mitosis/cytokinesis in the mutant. Thus, the failure of $r n r 4 \Delta$ mutant cells to reach truly STAT phase may make them more vulnerable to the genotoxic action of $\mathrm{SnCl}_{2}$. Yeast LOG cells are known to be highly sensitive to $\mathrm{SnCl}_{2}$, i.e., an exposure to a thousand-fold lower $\mathrm{SnCl}_{2}$ concentration than that used with STAT cells has the same cytotoxicity, this effect being independent of repair or anti-ROS protection genes (Viau et al., 2006).

Genetics and Molecular Research 7 (1): 1-6 (2008) www.funpecrp.com.br 


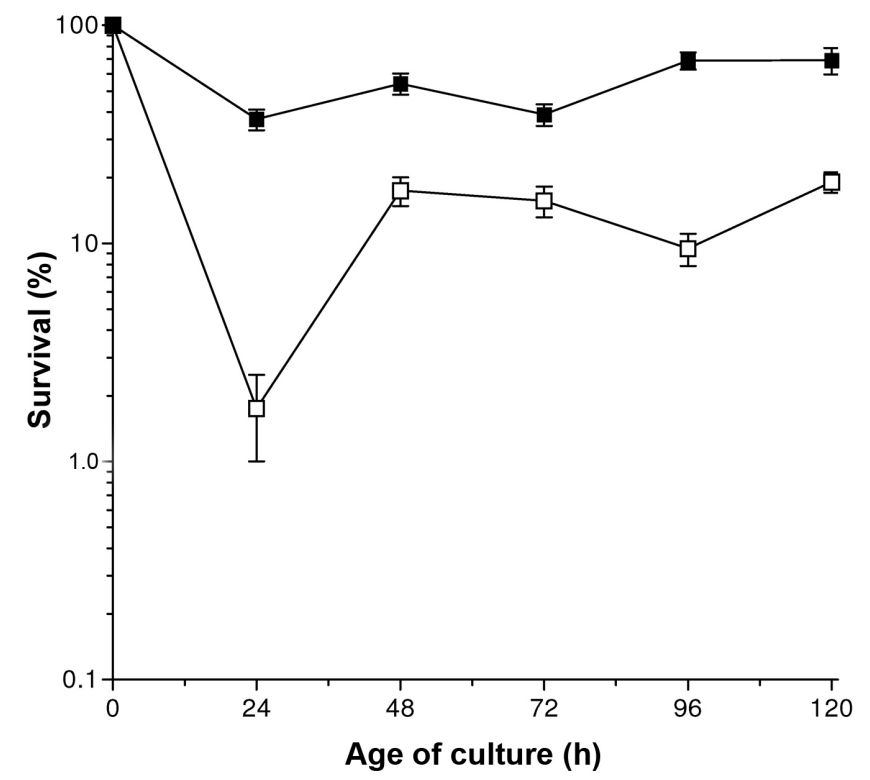

Figure 1. Sensitivity to $\mathrm{SnCl}_{2}$ exposure $(1 \mathrm{~h}, 25 \mathrm{mM})$ of WT and $r n r 4 \Delta$ mutant grown for up to 5 days in liquid

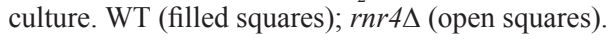

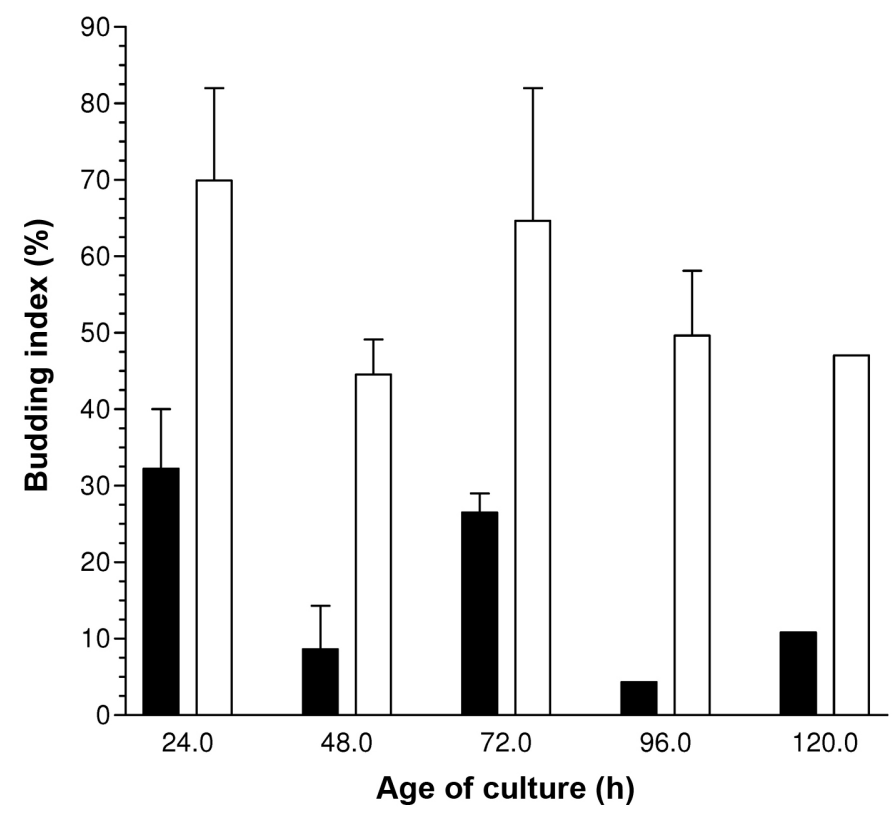

Figure 2. Budding index of WT (filled columns) and $r n r 4 \Delta$ (open columns) strains during 5 days in liquid culture. Error bars are not visible when deviation is very small. 
A yeast cell in STAT phase has an intrinsic acquired higher resistance to most genotoxic agents (with the exception of some radiation damage) as it has a dramatically changed metabolism with respect to many stress factors, amongst them metal import, exogenous or endogenous ROS; exponentially growing (LOG) cells, on the other hand, interact highly with the environment in that there is abundant transport via the membranes (active import and export permeases). Thus, LOG cells are much more sensitive to toxic metals, as active transport of one exogenously abundant metal ion, e.g., $\mathrm{Sn}^{2+}$, interferes negatively with metal homeostasis, which in turn may cause severe metabolic disturbances, leading to cell death (Viau C, personal communication).

The failure of $r n r 4 \Delta$ mutants to reach a true STAT phase, therefore, may explain their higher sensitivity to $\mathrm{SnCl}_{2}$. This would imply that failure to complete mitosis/cytokinesis after up to 5 days in liquid culture would be associated with some metabolic steps typical of LOG cells. The lower processivity of RNR in an $r n r 4 \Delta$ mutant (Y1Y3Y2Y2) that is due to the replacement of the small subunit heterodimer Y2Y4 by the homodimer Y2Y2 leaves the cell with significantly lower-than-normal dNTP pools (Perlstein et al., 2005). These nonadequate dNTP pools lead to somewhat slower cell growth and to significantly increased UVC sensitivity apparently by not allowing efficient repair of DNA damage in $r n r 4 \Delta$ (Strauss et al., 2007) and in the mutant harboring the leaky RNR4 mutant allele pso3-1 (Henriques and Moustacchi, 1980; Cassier et al., 1980; Brendel et al., 1998). The observed sensitivity to $\mathrm{SnCl}_{2}$ of the mutant $r n r 4 \Delta$ may thus reflect the (partial) loss of capacity to repair DNA damage. The increased $\mathrm{Sn}^{2+}$ sensitivity of several repair mutants is on the same order of magnitude as that seen for $r n r 4 \Delta$ (Viau et al., 2006), and the lack of UVC-induced mutagenesis in $r n r 4 \Delta$ points to impaired function of error-prone translesion repair processes (Strauss et al., 2007). It is, therefore, most plausible that an $r n r 4 \Delta$ mutant cell will show a moderate higherthan-WT sensitivity to $\mathrm{SnCl}_{2}$ regardless of cell age (i.e., its LOG or STAT status). This was verified by comparing the $\mathrm{SnCl}_{2}$ sensitivity of WT and $r n r 4 \Delta$ mutant cells in LOG phase, where exponentially growing $r n r 4 \Delta$ mutant cells were again 3-4 times more sensitive than cells of the isogenic WT in the same growth phase (data not shown). Thus, the most plausible explanation is that the generally higher $\mathrm{Sn}^{2+}$ sensitivity of the $r n r 4 \Delta$ mutant is due to its lowerthan-WT dNTP pools that impair the repair of $\mathrm{SnCl}_{2}$-induced DNA lesions.

\section{ACKNOWLEDGMENTS}

Research supported by Conselho Nacional de Desenvolvimento Científico e Tecnológico (CNPq) and Fundação de Amparo à Pesquisa do Estado da Bahia (FAPESB). T.S. Basso held a FAPESB fellowship and is a Master's student in the Genetics Post-Graduation Program of UESC. C. Pungartnik held a fellowship by PRODOC/FAPESB/CNPq, and M. Brendel is a Visiting Scientist supported by FAPESB.

\section{REFERENCES}

An X, Zhang Z, Yang K and Huang M (2006). Cotransport of the heterodimeric small subunit of the Saccharomyces cerevisiae ribonucleotide reductase between the nucleus and the cytoplasm. Genetics 173: 63-73.

Bernardo-Filho M, Cunha MC, Valsa IO, de Araujo AC, et al. (1994). Evaluation of potential genotoxicity of stannous chloride: inactivation, filamentation and lysogenic induction of Escherichia coli. Food Chem. Toxicol. 32: 477-479.

Brendel M (1985). Mutation induction by excess deoxyribonucleotides in Saccharomyces cerevisiae. In: Genetic

Genetics and Molecular Research 7 (1): 1-6 (2008) www.funpecrp.com.br 
Consequences of Nucleotide Pool Imbalance (Serres FJ de, ed.). Plenum Press, New York, 425-434.

Brendel M, Grey M, Maris AF, Hietkamp J, et al. (1998). Low glutathione pools in the original pso3 mutant of Saccharomyces cerevisiae are responsible for its pleiotropic sensitivity phenotype. Curr. Genet. 33: 4-9.

Burke D, Dawson D and Stearns T (2000). Methods in yeast genetics. Cold Spring Harbor Laboratory Course Manual. CSH Laboratory Press, New York.

Cassier C, Chanet R, Henriques JA and Moustacchi E (1980). The effects of three PSO genes on induced mutagenesis: a novel class of mutationally defective yeast. Genetics $96:$ 841-857.

Chabes A, Georgieva B, Domkin V, Zhao X, et al. (2003). Survival of DNA damage in yeast directly depends on increased dNTP levels allowed by relaxed feedback inhibition of ribonucleotide reductase. Cell 112: 391-401.

Dantas FJ, Moraes MO, Carvalho EF, Valsa JO, et al. (1996). Lethality induced by stannous chloride on Escherichia coli AB1157: participation of reactive oxygen species. Food Chem. Toxicol. 34: 959-962.

Dantas FJ, Moraes MO, de Mattos JC, Bezerra RJ, et al. (1999). Stannous chloride mediates single strand breaks in plasmid DNA through reactive oxygen species formation. Toxicol. Lett. 110: 129-136.

Elledge SJ, Zhou Z, Allen JB and Navas TA (1993). DNA damage and cell cycle regulation of ribonucleotide reductase. Bioessays 15: 333-339.

Henriques JA and Moustacchi E (1980). Isolation and characterization of pso mutants sensitive to photo-addition of psoralen derivatives in Saccharomyces cerevisiae. Genetics 95: 273-288.

Huang M and Elledge SJ (1997). Identification of RNR4, encoding a second essential small subunit of ribonucleotide reductase in Saccharomyces cerevisiae. Mol. Cell. Biol. 17: 6105-6113.

Klinkenberg LG, Webb T and Zitomer RS (2006). Synergy among differentially regulated repressors of the ribonucleotide diphosphate reductase genes of Saccharomyces cerevisiae. Eukaryot. Cell 5: 1007-1017.

Lee JD and Elledge SJ (2006). Control of ribonucleotide reductase localization through an anchoring mechanism involving Wtm1. Genes Dev. 20: 334-344.

McLean JR and Kaplan JG (1979). The effect of tin on unscheduled and semi-conservative DNA synthesis. In: The Molecular Basis of Immune Cell Function (Kaplan JG, ed.). Elsevier Biomedical, Amsterdam, 172-181.

McLean JR, Birnboim HC, Pontefact R and Kaplan JG (1983). The effect of tin chloride on the structure and function of DNA in human white blood cells. Chem. Biol. Interact. 46: 189-200.

Perlstein DL, Ge J, Ortigosa AD, Robblee JH, et al. (2005). The active form of the Saccharomyces cerevisiae ribonucleotide reductase small subunit is a heterodimer in vitro and in vivo. Biochemistry 44: 15366-15377.

Pungartnik C, Viau C, Picada J, Caldeira-de-Araujo A, et al. (2005). Genotoxicity of stannous chloride in yeast and bacteria. Mutat. Res. 583: 146-157.

Strauss M, Grey M, Henriques JA and Brendel M (2007). RNR4 mutant alleles pso3-1 and $r n r 4 \Delta$ block induced mutation in Saccharomyces cerevisiae. Curr. Genet. 51: 221-231.

Stubbe J and van Der Donk WA (1998). Protein radicals in enzyme catalysis. Chem. Rev. 98: 705-762.

Thelander L and Reichard P (1979). Reduction of ribonucleotides. Annu. Rev. Biochem. 48: 133-158.

Viau C, Pungartnik C, Schmitt MC, Basso TS, et al. (2006). Sensitivity to $\mathrm{Sn}^{2+}$ of the yeast Saccharomyces cerevisiae depends on general energy metabolism, metal transport, anti-oxidative defences, and DNA repair. Biometals 19: 705-714.

Wang PJ, Chabes A, Casagrande R, Tian XC, et al. (1997). Rnr4p, a novel ribonucleotide reductase small-subunit protein. Mol. Cell. Biol. 17: 6114-6121.

Yao R, Zhang Z, An X, Bucci B, et al. (2003). Subcellular localization of yeast ribonucleotide reductase regulated by the DNA replication and damage checkpoint pathways. Proc. Natl. Acad. Sci. USA 100: 6628-6633.

Genetics and Molecular Research 7 (1): 1-6 (2008) www.funpecrp.com.br 